\title{
A Genre-analysis of the Discussion Section of Iranian and English ELT Theses: A Comparative Study
}

\author{
Yassaman Hosseini Massoum \\ English Department, Imam Reza University, Felestin Sq., Mashhad, Khorasan Razavi, Iran \\ Elham Yazdanmehr \\ English Department, Attar Institute of Higher Education, 43 Kosar St., Mashhad, Khorasan Razavi, Iran
}

\begin{abstract}
The present research aimed to conduct a genre analysis of native (English) and non-native (Iranian) English speakers' M.A theses of Teaching English as a Foreign Language (TEFL) students to find any significant differences in their Discussion section structures according to the constitutive moves and steps. It also aimed to explore and compare the distribution of obligatory, conventional and optional moves and steps in the two corpuses. To this aim, 20 theses were randomly selected from well-known English Speaking Universities (Portland State University, University of Toledo, Ohio State University and University of Birmingham) to compare with 20 theses from Iran. The move analysis model by Yang and Allison (2003) was employed, which was specifically used in Applied Linguistics. Chi-squared test was run to make the comparison. The results revealed statistically significant differences between the genre followed in the Discussion sections of Iranian and non-Iranian TEFL M.A. theses. The most significant divergence was found in summarizing the study. English-speaking TEFL thesis writers tended to summarize the study in Discussion section significantly more than Iranian writers. Statistically significant differences were also found in the distribution of obligatory, conventional and optional moves. English-speaking writers indicated limitations in the Discussion section significantly more than Iranian writers. This shows Iranian TEFL M.A. writers are more reserved to discuss limitations. These results can be used effectively in M.A. courses of TEFL to raise students' awareness and prevent them from overstating or understating certain constituent parts of the Discussion section in theses.
\end{abstract}

Index Terms-discussion, TEFL, genre, genre analysis

\section{INTRODUCTION}

The significance of understanding genre to help language learners to comprehend and master academic, educational or professional discourse has been widely approved in the past two decades (Swales, 2004). Genre is a class of communicative event in which language plays the main role. Genre analysis discovers discourse structures in the wide context of a communicative event and tries to provide the basis for discourse structures in terms of author's purposes and influential settlements (Swales, 1990).

The Discussion section of a thesis/dissertation is presented as a mirror image of the Introduction section (Swales, 1990) and it plays a significant role in research articles in which the author tries to share his or her findings (Basturkmen, 2012). According to Weissberg and Buker (1990), authors attempt to inform readers of the results from specific to more general information and guide them with how findings should be viewed and interpreted. Or as Pojanapunya and Todd (2011) stated, this may be due to writers' need to meet the cognitive claims of Discussion sections and to have the accurate skills for writing in substantial argumentative styles.

Yet, besides the claims of scholars in the fields of English as a Foreign Language (EFL) and English as a Second language (ESL) such as Swales and Feak (2004), it is also commonly understood that the Discussion section is difficult to write for both native and non-native speakers of English (Swales, 1990; Swales \& Feak, 2004; Basturkmen, 2012; Weissberg \& Buker 1990, Pojanapunya \& Todd, 2011; Yang \& Allison, 2003).

The reason for this variation may be caused by the exact place in the research report which belongs to the Discussion sub-genre. Swales and Feak (2004) claimed where the Discussion section is placed in the text implicitly indicates that the audience have read and understood all previous sections. According to Rasmeenin (2006), while some writers begin the Discussion section with summarizing results or even emphasizing the main findings, others prefer to answer the research questions. Hence, it is not unexpected that "this section is less uniformly structured than others" (Sereebenjapol, 2003, p. 3)

The particular problem Docherty and Smith (1999) noticed was that authors used "rhetoric" to make claims about their findings which "go beyond the data." Swales (1990) also drew attention to the repeated sets in Discussion sections. From this point of view, it seems that moves from specific to general are typically made recurrently on a relatively 
small scale as the various aspects of a study are revisited rather than in a single overall development. Repeated cycles in Discussion sections are also a feature of later studies (Holmes, 1997; Posteguillo, 1999).

\section{A. Purpose of the Study}

Considering the problems mentioned above, there is a dearth of research on the nature of written text from a genreanalytic perspective. The current study tries to recognize the certain move structure of M.A. theses' Discussion sections and provide pedagogical implications for EFL/ESL students. This study also aims to find, describe and compare the obligatory, conventional, and optional moves in the Discussion subgenre of a set of M.A. theses written by Iranian EFL learners and those of native speaking counterparts.

\section{B. Research Questions}

In line with the purpose of study as mentioned, the present research hopes to address the following questions: RQ1. What is the generic organization of the Discussion sections of Iranian MA theses in Applied Linguistics?

RQ2. What is the generic organization of Discussion sections of Native English Speakers' theses in Applied Linguistics?

RQ3. Are the differences between Iranian and Native English speakers' Discussion sections statistically significant?

RQ4. What are the obligatory, conventional, and optional moves in the Discussion subgenre of a set of M.A. theses written by Iranian ELT learners and those of their NS counterparts?

RQ5. Are the obligatory, optional and conventional moves in the Discussion sections of Iranian and native English discussions different in a statistically significant way?

\section{Research Hypotheses}

Accordingly, the following hypotheses can be presented:

HO1.There is no statistically significant difference between Iranian and Native English speakers' Discussion sections.

$\mathrm{HO} 2$. There is no statistically significant difference between obligatory, optional and conventional moves in the Discussion sections of Iranian and native English discussions.

\section{REVIEW OF THE RELATED LITERATURE}

Swales (1990) drew attention to the repeated sets in Discussion sections. From this perspective, it seems that moves from specific to general are typically made repeatedly on a relatively small scale as various aspects of a study are revisited rather than in a single overall development. Repeated cycles in Discussion sections are a feature of later studies (Holmes, 1997; Posteguillo, 1999). Posteguillo (1999) adopted Swales' eight-move version in his analysis of Discussion and Conclusion sections of a corpus of 30 Computer Science articles. He found some cyclic pattern between the moves and Statement of Results as a key obligatory element. However, the results of Posteguillo's study did not confirm Swales' claim since Swales (1990) considered Statement of results as a quasi-obligatory move and believed that most cyclical patterns begin with this move.

On the other hand, Dudley-Evans (1994) considered a three-part framework for Discussion including introduction, evaluation, and conclusion and proposed nine-move sequences for the Discussion section of an RA: 1) Information move, 2) Statement of result, 3) Finding, 4) (Un)expected outcome, 5) Reference to previous research, 6) Explanation, 7) Claim, 8) Limitation, and 9) Recommendation. Dudley-Evans (1994), in presenting his model, maintained that the main task of Introduction is setting the scene through reaffirming the aim of the study and presenting a summary of the work done, while the main part of the Discussion i.e. evaluation involves the key results and the authors' main assertions. Then, the main results and claims are summarized in the Conclusion. He (1994) added that the main move series are those involving the Statement of results or findings followed by a reference to previous research or a Claim also followed by a Reference to previous studies.

In a corpus-based study, Atai and Falah (2005) conducted some research on Results and Discussion sections of 80 Applied Linguistics research articles written by Iranian and native English authors based on Brett's (1994) model to analyze the Results section and Swales' (1990) model to analyze Discussion sections. They (2005) also investigated the use of Evaluated Entities and Ascribed Values in Discussion sections of Applied Linguistics articles using Thetela's (1997) model.

In another relevant study, Nguyen and Pramoolsook (2015) analyzed the move structure of Results and Discussion sections of 24 TESOL Master theses written by Vietnamese students, based on Chen and Kuo's (2012) framework and also a discourse-based interview with writers and their supervisors. Chen and Kuo (2012) modified Yang and Allison's (2003) model and designed a new framework for the Discussion and Results chapters of M.A. theses in Applied Linguistics. They replaced Move 1, Background Information, from Yang and Allison's (2003) model with 'Introducing the Discussions chapter', and proposed some more details for the steps of Move 1, 2 and 3 but the rest of their framework was exactly the same as Yang and Allison's (2003). Their analysis indicated that only 'Reporting major findings' is obligatory and the first four moves, which demonstrate the rhetorical functions of summarizing, evaluating, and deducing from the reported study of the M.A. thesis Discussion section, occurred more frequently. 
Among a body of research that employed Yang and Allison's (2003) move analysis model for investigation, Amnuai and Wannaruk (2013) studied the move structure of 60 English Applied Linguistics article Discussion sections published in Thai and international journals and they found that there was no linear sequencing of the moves in any Discussion section of the corpora. The most frequent move in both data was move 4 (Commenting on results) followed by move 2 (Reporting results). Move 4 was the obligatory move in two sets of the corpora and the other five moves were less frequent and were optional in the two corpora.

In a study similar to the present research, Nadoushan (2012) investigated the move structure of 46 Discussion sections of MA theses written in English by Iranian EFL students and compared its results with a study by Rasmeenin (2006) on the Discussion sections of 9 theses written by non-Iranian EFL students. He also indicated optional and obligatory moves and the frequency of each. According to his study, it was indicated that move 2 (Reporting results) was the most frequent move and move 5 (Summarizing the study) and move 6 (Evaluating the study) were the least frequent moves. However, in Yang and Allison's (2003) study, move 4 was the most frequently used and was considered an obligatory move. In Nadoushan's (2012) study, on the other hand, three moves (moves 2, 4 and 7) were classified as obligatory. The results of this study do not confirm the results of Yang and Allison's (2003) although the author believed that these mismatches were due to different sample sizes of 45 Discussion sections in Nadoushan's study versus 8 Discussion sections in Yang and Alisson's).

Zekrati (2015) also conducted some research on 32 Discussion sections of medical articles based on Yang and Allison's (2003) move analysis written by Iranian and non-Iranian nonnative authors. Based on the results of this study it was revealed that move 2 (Reporting the results) was the most frequent move, and the least frequent moves were move 5 (Summarizing the study) and move 3 (Summarizing the results). Mann-Whitney U test results indicated that there is a significant difference between Iranian writers and their non-Iranian counterparts regarding the frequency with which they use moves $1,3,5$, and 7 . There was no significant difference between the two groups in move 2 (Reporting results), move 4 (Commenting on results), and move 6 (Evaluating the study). According to the obtained data, it was revealed that moves 2, 4, 6 were obligatory in all articles written by Iranian and non-Iranian authors. Moves 3 and 7 were considered conventional, and finally, moves 1 and 5 were deemed optional.

\section{MethodOLOGY}

\section{A. Corpus}

There were two corpuses, from each a sample of 20 these were selected on a random basis. The Foreign sample were taken from 3 sources: Portland State University's website (www.pdx.edu), Ohio's Academic Library Consortium (www.ohiolink.edu) and the University of Birmingham's website (www.birmingham.ac.uk). The Iranian sample was taken from the International University of Imam Reza.

\section{B. Data Collection}

The 40 Discussion sections extracted from MA theses in Applied Linguistics written by Iranian ELT students and those of their NS counterparts. All 20 Iranian-written theses belong to M.A. ELT students of International University of Imam Reza who defended their dissertation from 2014 to 2019. The researcher asked students in person and their supervisors to send the PDF version of the theses through E-mail.

For the foreign corpus, the present researcher chose three established state universities in United States of America: Portland State University (PSU), Ohio State University (OSU), The University of Toledo (UT), and the University of Birmingham in United Kingdom. The data were selected on a stratified random basis. Five theses in ELT written and defended from 2014-2017 were downloaded from Portland State University's website (www.pdx.edu) which gave an open access for their M.A and Ph.D. dissertations in various majors including English Language Teaching. The researcher randomly selected 5 M.A theses in ELT written and defended from 2011 to 2015 from the University of Birmingham's website (www.birmingham.ac.uk) which also gave an open access for their M.A and Ph.D. dissertations; and the rest of the data (5 from The University of Toledo and 5 from Ohio State University) were downloaded from (www.ohiolink.edu). The theses which belonged to OSU were written and defended from 2010-2017 while TU's defended theses belonged to 2010-2016.

\section{Data Analysis}

The data were analyzed qualitatively by the author. Each Discussion section of the theses was read and analyzed by the researcher, using Yang and Allison's (2003) specific model designed for the move analysis of Applied Linguistics RAs. This model includes some specific moves and steps defined in Instrumentation.

After corpus collection, each Discussion section was given a specific code (e.g., D\#1, D\#2, D\#3 ... D\#40). Then, a frequency count was applied to find the total number of words in each Discussion. The data were also analyzed to find, describe and compare the obligatory, conventional, and optional moves in the 'Discussion' subgenre of a set of M.A. theses. Accordingly, this research followed Amnui and Wannaruk's (2013) criteria for justifying and classifying each move in genre analysis of articles or dissertations as 'obligatory', 'conventional' or 'optional'. According to Amnui and Wannaruk's (2013), if the degree of occurrence of a move in each piece of research work is $100 \%$, it is classified as 
'obligatory'. If a degree of occurrence of a move is below $60 \%$, it is considered as 'optional' and if it ranges from 60 $99 \%$, it can be regarded as 'conventional'.

Accordingly, the frequencies and percentages for each move in each Discussion section was found and the results were used as the data. To find any significant difference in the move frequency of the Discussion sub-genre of MA theses written by Iranian EFL students and their NS counterparts, the perceived move frequencies in the current study were compared and contrasted. A chi-squared test was run to make the comparison possible.

\section{Instrumentation}

The instrument selected in this study was Yang and Allison's (2003) analytic model of the Discussion section which consists of seven rhetorical moves including some steps:

Move 1: Background information

Move 2: Reporting results

Move 3: Summarizing results

Move 4: Commenting on results

Step 1: Interpreting results

Step 2: Comparing results with literature

Step 3: Accounting for results

Step 4: Evaluating results

Move 5: Summarizing the study

Move 6: Evaluating the study

Step 1: Indicating limitations

Step 2: Indicating significance/advantage

Step 3: Evaluating methodology

Move 7: Deductions from the research

Step 1: Making suggestions

Step 2: Recommending further research

Step 3: Drawing pedagogic implication

\section{RESUlts}

\section{A. Answer to $R Q 1$}

The first question in this research investigated the genre of Discussion section in Iranian TEFL M.A. theses. There were 7 moves in the model, some followed by certain steps, the distribution of which is summarized in Table 1.

TABLE.1

DisTRIBUTION OF DiSCUSSION MOVES AND STEPS IN THE IRANIAN CORPUS (N=20)

\begin{tabular}{lll}
\hline Move/Step & Frequency $(\mathbf{f})$ & Percentage $(\boldsymbol{\%})$ \\
\hline Move1 & 19 & 95 \\
\hline Move2 & 20 & 100 \\
\hline Move3 & 14 & 70 \\
\hline Move4 & 20 & 100 \\
\hline Step4.1 & 20 & 100 \\
\hline Step4.2 & 17 & 85 \\
\hline Step4.3 & 20 & 100 \\
\hline Step4.4 & 18 & 90 \\
\hline Move5 & 13 & 65 \\
\hline Move6 & 17 & 85 \\
\hline Step6.1 & 14 & 70 \\
\hline Step6.2 & 11 & 55 \\
\hline Step6.3 & 15 & 75 \\
\hline Move7 & 17 & 85 \\
\hline Step7.1 & 16 & 80 \\
\hline Step7.2 & 15 & 75 \\
\hline Step7.3 & 17 & 85 \\
\hline
\end{tabular}

As it can be observed in the Table above, the most frequent Moves followed in the Iranian corpus were Move 4 (Commenting on results) and Move 2 (Reporting results) while the least frequent Move was Move 5 (Summarizing the study). The rest fall somewhere in between these Min. and Max. frequencies of range. Among all Steps, the most frequent steps were Steps 1 (Interpreting results) and 3 (Accounting for results) of Move 4 which existed in the whole corpus. The distribution of Moves is also summarized in a pie-chart indicated in Figure 4.1 which helps to compare the prevalence of Moves within the Iranian corpus. 


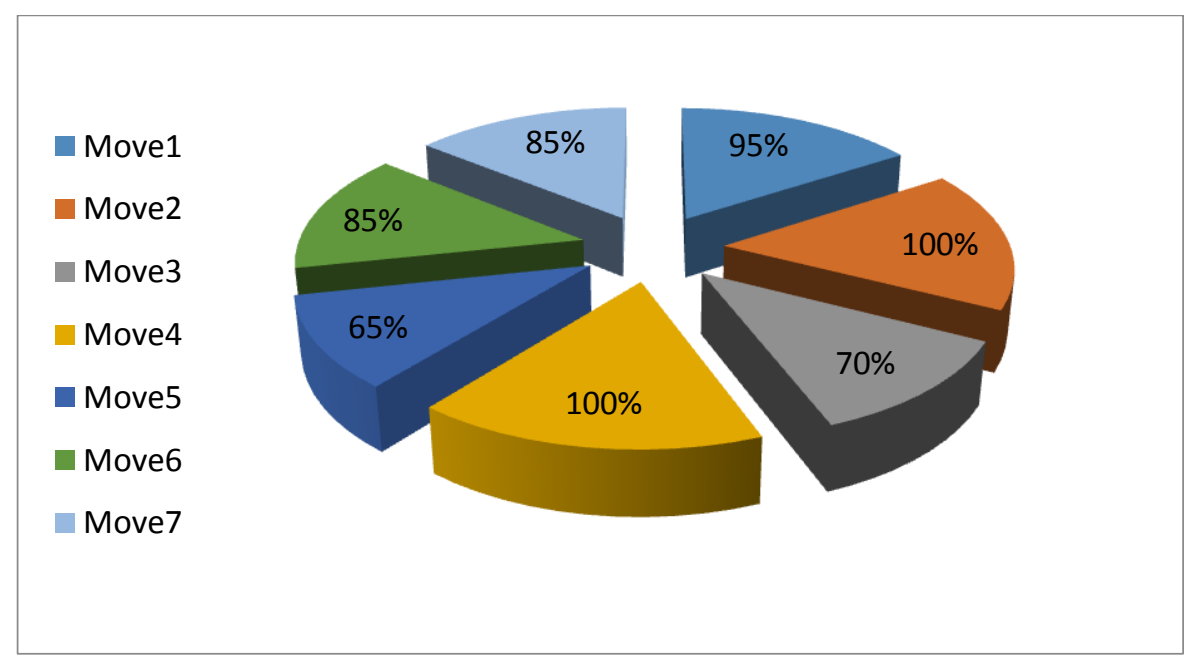

Figure 1. Distribution of discussion moves in the Iranian corpus

As evident in Figure 4.1, the highest percentages among Moves belong to Moves 2 and 4 (100\%) and the lowest is that of Move $5(65 \%)$. This is in fact:

Reporting results, Commenting on results > Background information > Evaluating the study, Deducing from research $>$ Summarizing results $>$ Summarizing the stud

\section{B. Answer to RQ2}

The second research question in the present study explored the genre of Discussion sections in non-Iranian M.A. theses in TEFL written in English-speaking countries. Table 2 summarizes the distribution of Moves and Steps in the Discussion section of this corpus.

TABLE 2

DisTRIBUTION OF DiSCUSSION MOVES AND STEPS IN THE NON-IRANIAN CORPUS (N=20)

\begin{tabular}{lll}
\hline Move/Step & Frequency $(\mathbf{f})$ & Percentage $(\boldsymbol{\%})$ \\
\hline Move1 & 20 & 100 \\
\hline Move2 & 19 & 95 \\
\hline Move3 & 18 & 90 \\
\hline Move4 & 20 & 100 \\
\hline Step4.1 & 20 & 100 \\
\hline Step4.2 & 18 & 90 \\
\hline Step4.3 & 20 & 100 \\
\hline Step4.4 & 15 & 75 \\
\hline Move5 & 19 & 95 \\
\hline Move6 & 19 & 95 \\
\hline Step6.1 & 8 & 40 \\
\hline Step6.2 & 6 & 30 \\
\hline Step6.3 & 18 & 90 \\
\hline Move7 & 19 & 95 \\
\hline Step7.1 & 19 & 95 \\
\hline Step7.2 & 19 & 95 \\
\hline Step7.3 & 18 & 90 \\
\hline
\end{tabular}

As it can be observed in the Table above, the most frequent Moves followed in the non-Iranian corpus were Moves 1 and 4 (Background information and Commenting on results, respectively) (100\%). Yet, the least frequent was Move 3 (Summarizing results), though the percentage was high (90\%).

Among all Steps, the most frequent were Steps 4.1 and 4.3 (100\%). These stood for Interpreting the results and Accounting for results (100\%). The least frequent were Steps 6.1 and 6.2 which represented Indicating limitations and Indicating advantages, respectively. Their percentage of occurrence was $40 \%$ and $30 \%$. The Steps follow the order below in terms of prevalence in the non-Iranian corpus:

Interpreting results, Accounting for results $>$ Making suggestions, Recommending further research $>$ Comparing results with literature, Evaluating methodology, Recommending further research $>$ Evaluating results $>$ Indicating limitations > Indicating significance/advantage

The distribution of Moves is also summarized in a pie-chart indicated in Figure 2 which helps to compare the prevalence of moves in the non-Iranian corpus. 


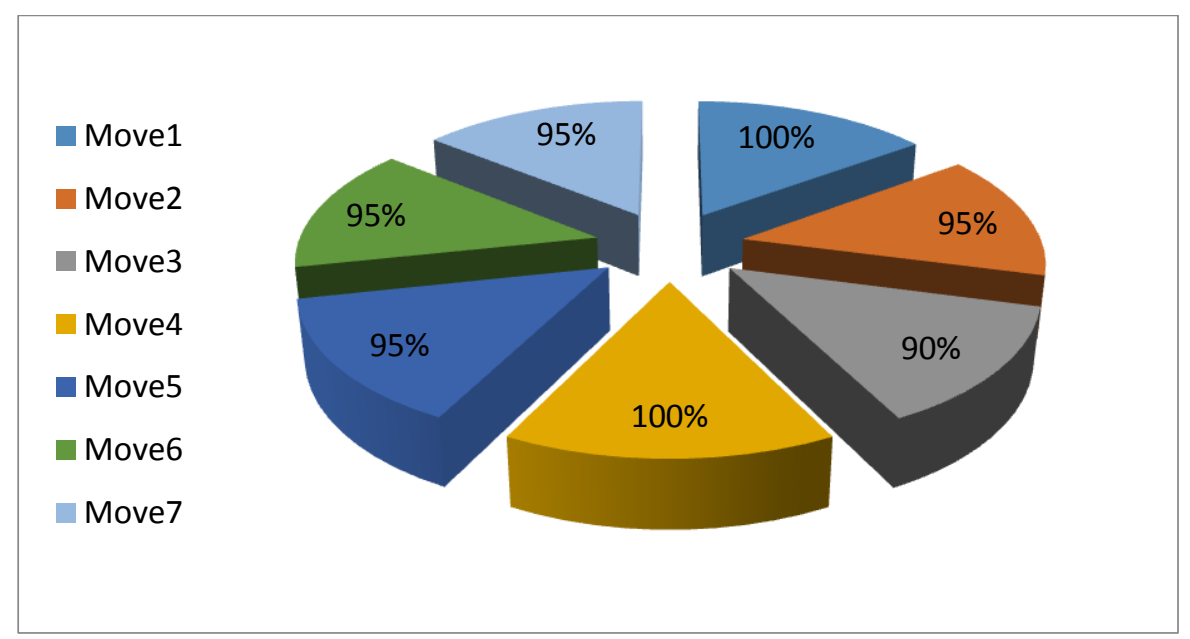

Figure 2. Distribution of discussion moves in the non-Iranian corpus

As evident in Figure 2, the highest percentages among Moves belonged to Move 1 and 4 (100\%) and the lowest was that of Move $3(90 \%)$. The Moves are presented in the following order of frequency in the Iranian corpus:

Background information, Commenting on results > Reporting results, Summarizing the study, Evaluating the study, Deductions from the research $>$ Summarizing results

\section{Answer to $R Q 3$}

The first two research questions explored the genre of Discussion sections in Iranian and non-Iranian TEFL M.A. theses written in English. A null hypothesis was presented for this which stated there is no statistically significant difference between the two corpuses in terms of the Moves and Steps followed in Discussion section. Certain differences emerged. Yet, in order to know whether these differences were statistically significant or not, Chi-squared test was run and the results are presented as below.

TABLE 3.

COMPARISON OF GENRES BETWEEN THE TWO CORPUSES

\begin{tabular}{|c|c|c|c|}
\hline Move1 & Iranian corpus & Non-Iranian corpus & $\chi^{2}$ and sig. \\
\hline absent & 5 & .0 & .160 \\
\hline present & 95 & 100 & Sig. .311 \\
\hline Move2 & Iranian corpus & Non-Iranian corpus & $\chi^{2}$ and sig. \\
\hline absent & 0 & 5 & .160 \\
\hline present & 100 & 95 & Sig. .311 \\
\hline Move3 & Iranian corpus & Non-Iranian corpus & $\chi^{2}$ and sig. \\
\hline absent & 30 & 10 & .250 \\
\hline present & 70 & 90 & Sig. .114 \\
\hline Move4 & Iranian corpus & Non-Iranian corpus & $\chi^{2}$ and sig. \\
\hline absent & 0 & 0 & -- \\
\hline present & 100 & 100 & -- \\
\hline Move5 & Iranian corpus & Non-Iranian corpus & $\chi^{2}$ and sig. \\
\hline absent & 35 & 5 & .375 \\
\hline present & 65 & 95 & Sig. .018 \\
\hline Move6 & Iranian corpus & Non-Iranian corpus & $\chi^{2}$ and sig. \\
\hline absent & 15 & 5 & .167 \\
\hline present & 85 & 95 & Sig. .292 \\
\hline Move 7 & Iranian corpus & Non-Iranian corpus & $\chi^{2}$ and sig. \\
\hline absent & 15 & 5 & .167 \\
\hline present & 85 & 95 & Sig. .292 \\
\hline
\end{tabular}

The points of divergence seem to lie in all Moves (except for Move 4), yet not all are statistically significant. As for Move 1 (Background information), the non-Iranian corpus seems to contain this Move more than the Iranian. Exactly the opposite case is true about Move 2 (Reporting results). As for Move 3 (Summarizing results), the non-Iranian corpus seems to follow it more than the Iranian corpus. The two corpuses appear to contain Move 4 (Commenting on results) to the same degree. Thus, there is no difference between the two corpuses in terms of this Move. Therefore, no chi-squared was estimated for this Move. Yet, for Move 5 (Summarizing the study), the non-Iranian corpus contains this Move more than the Iranian corpus. Moves 6 (Evaluating the study) and 7 (Deductions from research) prevail to the same extent in both corpuses.

The statistically significant difference between the two corpuses was found only in Move 5 which stood for Summarizing the study. This move was significantly more prevalent in the non-Iranian corpus than the Iranian. In other words, English-speaking M.A. TEFL thesis writers tend to provide a summary of findings much more than Iranian writers, and this divergence between the two is statistically significant. Thus, the null hypothesis can be rejected. A 
better comparison can be seen between the two corpuses as visually presented in Figure 3 . Percentages can be crosscompared.

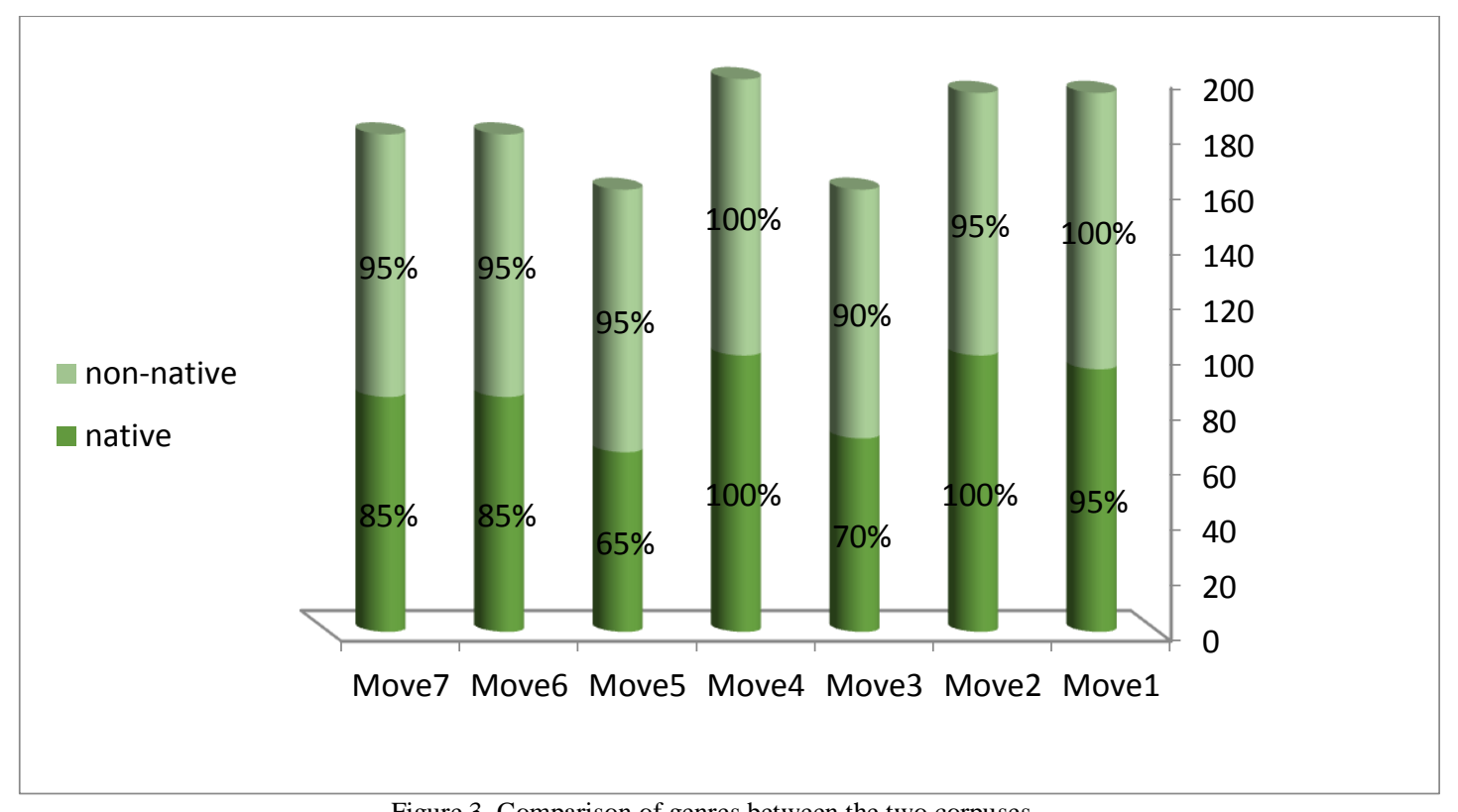

Figure 3. Comparison of genres between the two corpuses

As it can be observed, Move 5 contains the sharpest difference between the two corpuses whereas Move 4 shows no difference. Besides the Moves, the frequency of Steps was also compared between groups and the chi-squared test was run to find statistically significant differences. Table 4 shows the results of chi-squared test for the constituent Steps of Move 4. These Steps include: Interpreting results (4.1), Comparing results with literature (4.2), Accounting for results (4.3) and Evaluating results (4.4).

TABLE 4.

CHI-SQUARED TEST RESUlTS FOR THE STEPS OF MOVE 4 IN TWO CORPUSES

\begin{tabular}{llll}
\hline Step 4.1 & Iranian corpus & Non-Iranian corpus & $\chi^{2}$ and sig. \\
\hline absent & 0 & 0 & -- \\
\hline present & 100 & 100 & -- \\
\hline Step 4.2 & Iranian corpus & Non-Iranian corpus & $\chi^{\mathbf{2}}$ and sig. \\
\hline absent & 15 & 10 & .076 \\
\hline present & 85 & 90 & Sig. .633 \\
\hline Step 4.3 & Iranian corpus & Non-Iranian corpus & $\chi^{\mathbf{2}}$ and sig. \\
\hline absent & 0 & 0 & -- \\
\hline present & 100 & 100 & -- \\
\hline Step 4.4 & Iranian corpus & Non-Iranian corpus & $\chi^{\mathbf{2}}$ and sig. \\
\hline absent & 10 & 25 & .197 \\
\hline present & 90 & 75 & Sig. .212 \\
\hline
\end{tabular}

As it can be observed in the Table above, there is no statistically significant difference between the two corpuses (Iranian and non-Iranian) in the four Steps of Move 4. In Table 5. below, the two corpuses are compared in terms of all Steps of Move 6. These Steps include Indicating limitations (6.1), Indicating advantage/significance (6.2), Evaluating methodology (6.3).

TABLE 5.

CHI-SQUARED TEST Results FOR THE STEPS OF MOVE 6

\begin{tabular}{llll}
\hline Step 6.1 & Iranian corpus & Non-Iranian corpus & $\chi^{\mathbf{2}}$ and sig. \\
\hline absent & 30 & 60 & .302 \\
\hline present & 70 & 40 & Sig. .057 \\
\hline Step 6.2 & Iranian corpus & Non-Iranian corpus & $\chi^{\mathbf{2} \text { and sig. }}$ \\
\hline absent & 45 & 70 & .253 \\
\hline present & 55 & 30 & Sig. .110 \\
\hline Step 6.3 & Iranian corpus & Non-Iranian corpus & $\chi^{\mathbf{2} \text { and sig. }}$ \\
\hline absent & 25 & 10 & .197 \\
\hline present & 75 & 90 & Sig. .212 \\
\hline
\end{tabular}

Except for Step 6.1 (Indicating limitations), the other Steps do not make any statistically significant difference between the two corpuses. Similarly, Table 6 below shows chi-squared test results for the Steps of Move 7. These Steps include: Making suggestions (7.1), Recommending further research (7.2), Drawing pedagogic implications (7.3). 
TABLE 6.

CHI-SQUARED TEST RESULTS FOR THE STEPS OF MOVE 7

\begin{tabular}{llll}
\hline Step 7.1 & Iranian corpus & Non-Iranian corpus & $\chi^{2}$ and sig. \\
\hline absent & 20 & 5 & .227 \\
\hline present & 80 & 95 & Sig. .151 \\
\hline Step 7.2 & Iranian corpus & Non-Iranian corpus & $\chi^{2}$ and sig. \\
\hline absent & 25 & 5 & .280 \\
\hline present & 75 & 95 & Sig. .077 \\
\hline Step 7.3 & Iranian corpus & Non-Iranian corpus & $\chi^{2}$ and sig. \\
\hline absent & 15 & 10 & .076 \\
\hline present & 85 & 90 & Sig. .633 \\
\hline
\end{tabular}

As it can be seen in the Table above, the differences between the two corpuses are not statistically significant in any Step of Move 7 (Sig>.05).

\section{Answer to $R Q 4$}

The fourth research question in the present study explored which Moves in the Iranian and non-Iranian corpus were obligatory, which were conventional and which were optional. This categorization was proposed by Rasmeenin (2006) according to whom, obligatory occurs when the Move is observed in $100 \%$ of the Discussions, conventional occurs when the Move is observed in $66 \%-99 \%$ of the Discussions and optional occurs when it is in less than $66 \%$ of the Discussions. Table 7 indicates the relevant results with this respect in the Iranian corpus:

TABLE 7

DISTRIBUTION OF OBLIGATORY, CONVENTIONAL AND OPTIONAL MOVES IN THE IRANIAN CORPUS

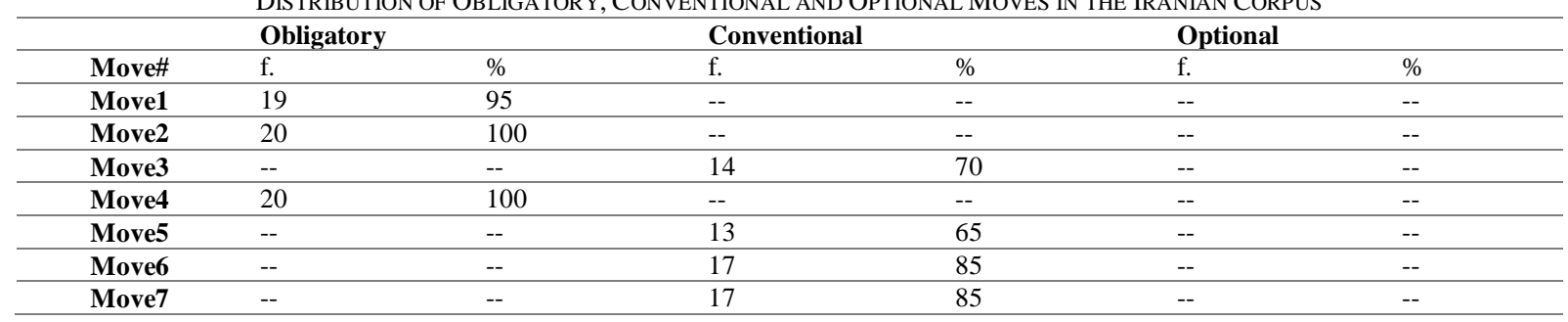

The information summarized in the Table above shows that in the Iranian corpus, the highest frequency is that of the Conventional Moves. Obligatory Moves were observed to be Moves 1, 2 and 4. Conventional Moves were mostly observable those in Moves 3, 5, 6 and 7. This information can be better traced visually in Figure 4.

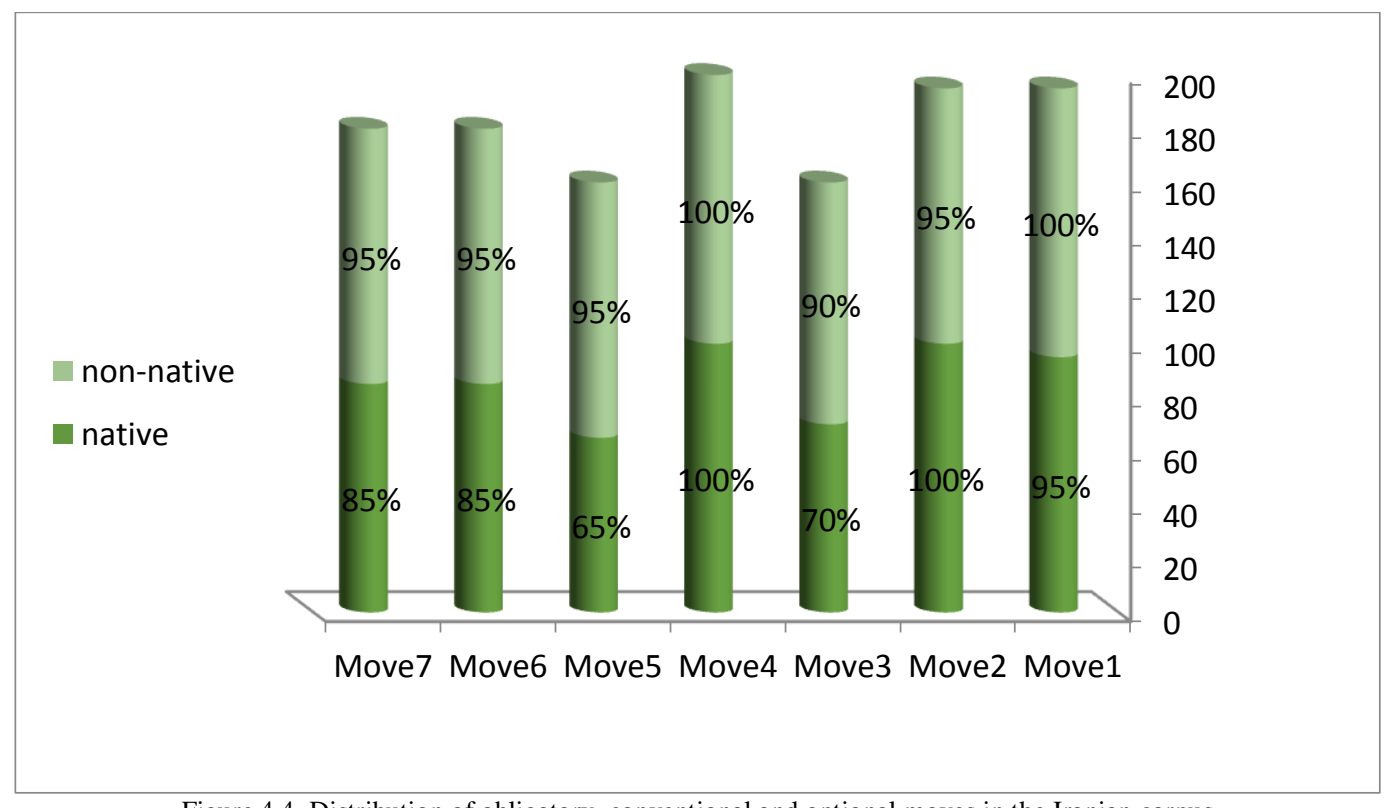

Figure 4.4. Distribution of obligatory, conventional and optional moves in the Iranian corpus

A similar analysis could be done for the Steps of the target Moves in the Iranian corpus. Therefore, the categories of Steps for all Moves are reported as below. 
TABLE 8

DisTRIBUTION OF OBLIGATORY, CONVENTIONAL AND OPTIONAL STEPS IN THE IRANIAN CORPUS

\begin{tabular}{|c|c|c|c|c|c|c|}
\hline \multirow[b]{2}{*}{ Step\#.\# } & \multicolumn{2}{|c|}{ Obligatory } & \multicolumn{2}{|c|}{ Conventional } & \multicolumn{2}{|c|}{ Optional } \\
\hline & f. & $\%$ & f. & $\%$ & f. & $\%$ \\
\hline Step 4.1 & 20 & 100 & -- & -- & -- & -- \\
\hline Step 4.2 & -- & -- & 17 & 85 & -- & -- \\
\hline Step 4.3 & 20 & 100 & -- & -- & -- & -- \\
\hline Step 4.4 & -- & -- & 18 & 90 & -- & -- \\
\hline Step 6.1 & -- & -- & 14 & 70 & -- & -- \\
\hline Step 6.2 & -- & -- & -- & -- & 11 & 55 \\
\hline Step 6.3 & -- & -- & 15 & 75 & -- & -- \\
\hline Step 7.1 & -- & -- & 16 & 80 & -- & -- \\
\hline Step 7.2 & -- & -- & 15 & 75 & -- & -- \\
\hline Step 7.3 & -- & -- & 17 & 85 & -- & -- \\
\hline
\end{tabular}

Among the constituent Steps of Move 4, Step 4.1 (Interpreting results) was found to be obligatory as it existed in all Discussion sections of the Iranian corpus. Step 4.2 (Comparing to literature) was found to be conventional as it prevailed in $85 \%$ of cases. Step 4.3 (Accounting for results) was categorized as obligatory as it appeared in all Discussion sections. Step 4.4 (Evaluating Results) was to be categorized as conventional as it occurred in $90 \%$ of the corpus. Among the Steps of Move 6, Step 6.1 (Indicating limitations) was found to be conventional as it occurred in $70 \%$ of the Iranian corpus. Step 6.2 (Indicating significance/advantage) was taken as optional since it occurred in 55\% of the corpus. Step 6.3 (Evaluating methodology) was categorized as conventional as it comprised $75 \%$ of the corpus. There were three Steps within Move 7, all of which (Making suggestions, Recommending further research, Drawing pedagogic implications) showed to belong to the conventional category. A similar procedure of analysis was conducted for the non-Iranian corpus first in terms of the Moves and the results can be observed in Table 9.

TABLE 9

DiSTRIBUTION OF OBLIGATORY, CONVENTIONAL AND OPTIONAL MOVES IN THE NON-IRANIAN CORPUS

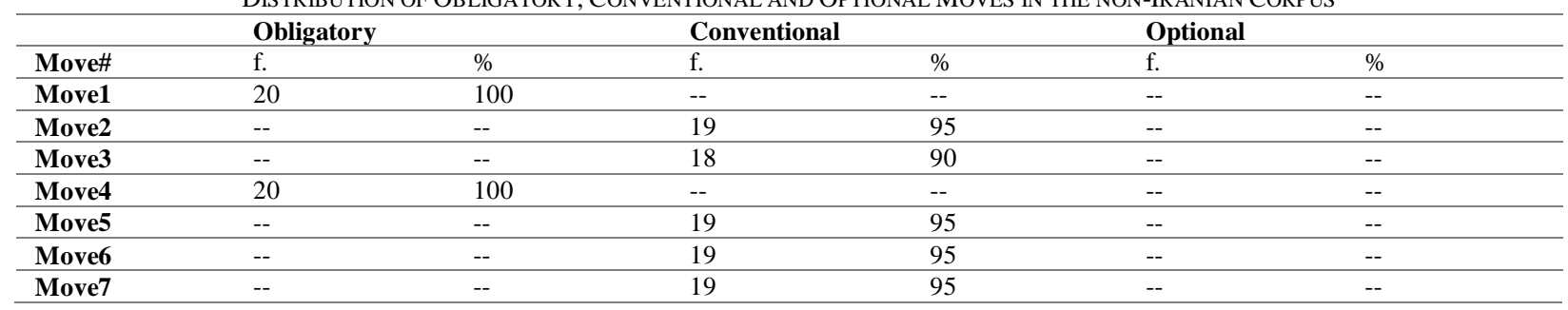

As indicated in Table 9, Move 1 (Background information) was found in the whole corpus. As its prevalence was $100 \%$, it was categorized as obligatory. As for Move2 (Reporting results), it occurred in $95 \%$ of cases. Thus, it could belong to the conventional category. Move 3 (Summarizing results) could be categorized as conventional too as it occurred in $90 \%$ of the corpus. Another obligatory Move showed to be Move 4 (Commenting on results) which prevailed in the whole corpus. Moves 5, 6 and 7 (Summarizing the study, Evaluating the study and Deductions from research) all showed to belong to the conventional category as they occurred in $95 \%$ of the corpus. The distribution of obligatory, conventional and optional Moves can be better compared in the following Figure.

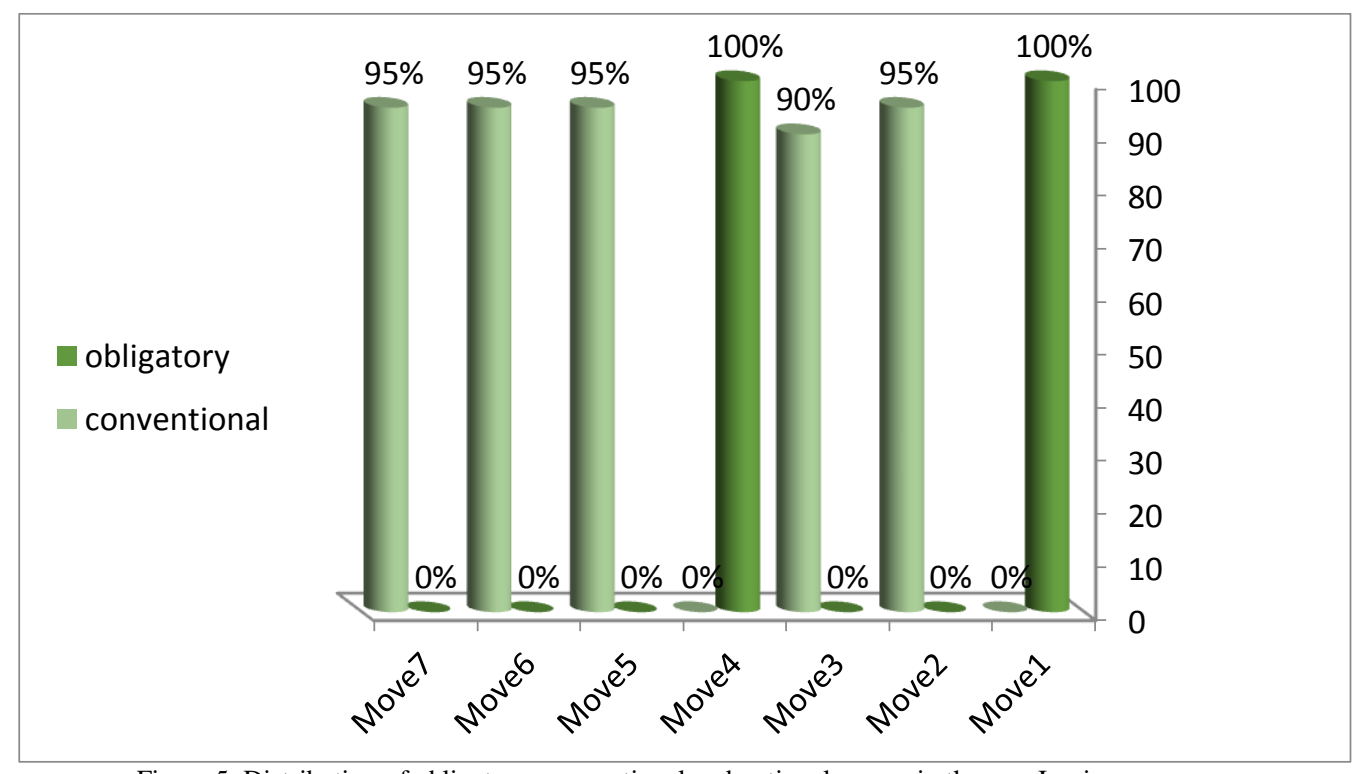

Figure 5. Distribution of obligatory, conventional and optional moves in the non-Iranian corpus 
As for Steps and their categorization as obligatory, conventional and optional, the results are comparable in Table 10.

TABLE 10

DisTRIBUTION OF OBLIGATORY, CONVENTIONAL AND OPTIONAL STEPS IN THE NON-IRANIAN CORPUS

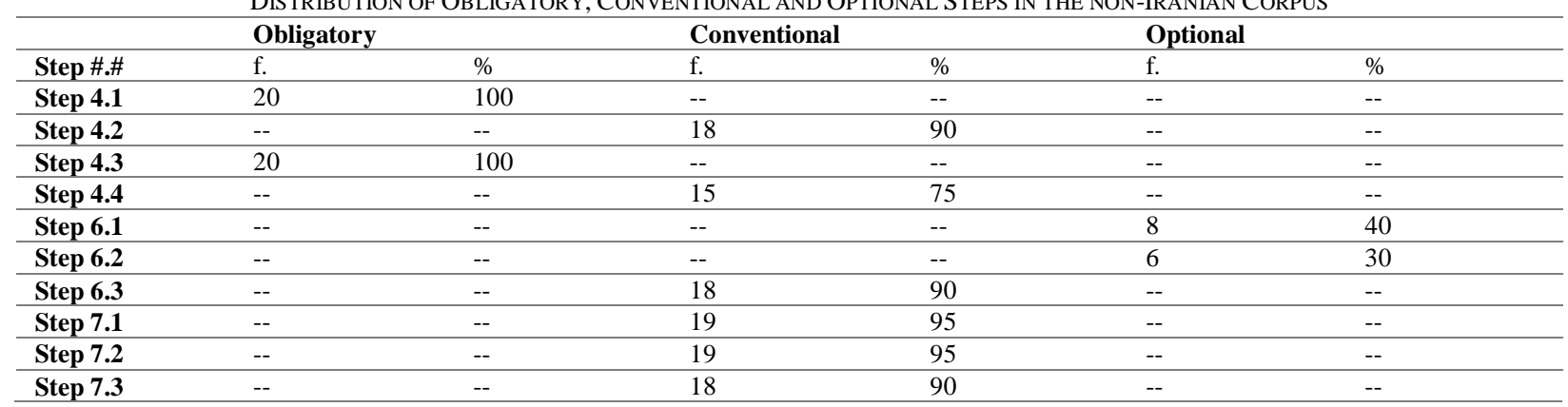

Move 4 was comprised of four Steps, the first of which (Interpreting results) showed to prevail in the whole corpus. Thus, it can be categorized as obligatory. The second Step (Comparing results with literature) was found to occur in $90 \%$ of the corpus. Thus, it belonged to the conventional category. The third Step (Accounting for results) was found to occur in the whole corpus which makes it an obligatory Step. The fourth Step (Evaluating results) existed in $75 \%$ of the cases which makes it a conventional Step. As for Move 6, there were three Steps which are analyzed here. The first Step (Indicating limitations) was found to be an optional Step as it prevailed in $40 \%$ of the corpus. The second Step (Indicating significance/advantage) was also an optional Step as it occurred in only $30 \%$ of the corpus. Move 7 consisted of three Steps 9 (Making suggestions, Recommending further research, Drawing pedagogic implications) all of which were found to be belong to the conventional category as they occurred, respectively, in $95 \%, 95 \%$ and $90 \%$ of the corpus.

\section{E. Answer to $R Q 5$}

The fifth question aimed to compare the two corpuses in terms of the distribution of obligatory, conventional and optional Moves and Steps. The second null hypothesis of the present study stated that there is no statistically significant difference between the two corpuses in terms of these. As the results showed, certain differences were observable. Yet, to know whether these differences were statistically significant or not, Chi-squared test was run and the results are presented once for Moves and once again for Steps below.

TABLE 11

COMPARISON OF THE IRANIAN AND NON-IRANIAN CORPUSES IN TERMS OF OBLIGATORY, CONVENTIONAL AND OPTIONAL MOVES

\begin{tabular}{|c|c|c|c|}
\hline Move 1 & Iranian corpus & Non-Iranian corpus & $\chi^{2}$ and sig. \\
\hline Conventional & 100 & 100 & - \\
\hline Move 2 & Iranian corpus & Non-Iranian corpus & $\chi^{2}$ and sig. \\
\hline Obligatory & 100 & -- & 1 \\
\hline Conventional & 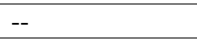 & 95 & Sig. .000 \\
\hline Move 3 & Iranian corpus & Non-Iranian corpus & $\chi^{2}$ and sig. \\
\hline Conventional & 70 & 90 & $\begin{array}{l}.250 \\
\text { Sig. .114 }\end{array}$ \\
\hline Move 4 & Iranian corpus & Non-Iranian corpus & $\chi^{2}$ and sig. \\
\hline Obligatory & 100 & 100 & -- \\
\hline Move 5 & Iranian corpus & Non-Iranian corpus & $\chi^{2}$ and sig. \\
\hline Conventional & 65 & 95 & $\begin{array}{l}.375 \\
\text { Sig. .018 }\end{array}$ \\
\hline Move 6 & Iranian corpus & Non-Iranian corpus & $\chi^{2}$ and sig. \\
\hline Conventional & 85 & 95 & $\begin{array}{l}.167 \\
\text { Sig. .292 }\end{array}$ \\
\hline Move 7 & Iranian corpus & Non-Iranian corpus & $\chi^{2}$ and sig. \\
\hline Conventional & 85 & 95 & $\begin{array}{l}.167 \\
\text { Sig. .292 }\end{array}$ \\
\hline
\end{tabular}

As it can be observed in the Table above, the two corpuses only diverge significantly in terms of conventional Moves $(3,5,6,7)$ which all existed significantly more in the non-Iranian corpus than the Iranian. A similar comparison was also made Table 4.12 between the two corpuses along Steps, as can be seen below. 
TABLE 12

COMPARISON OF THE IRANIAN AND NON-IRANIAN CORPUSES IN TERMS OF OBLIGATORY, CONVENTIONAL AND OPTIONAL STEPS

\begin{tabular}{llll}
\hline Step 4.1 & Iranian corpus & Non-Iranian corpus & $\chi^{2}$ and sig. \\
\hline Obligatory & 100 & 100 & 0 \\
\hline Step 4.2 & Iranian corpus & Non-Iranian corpus & $\chi^{2}$ and sig. \\
\hline Conventional & 85 & 90 & .076 \\
& & Sig. .633 \\
\hline Step 4.3 & Iranian corpus & Non-Iranian corpus & $\chi^{2}$ and sig. \\
\hline Obligatory & 100 & 100 & -- \\
\hline Step 4.4 & Iranian corpus & Non-Iranian corpus & $\chi^{2}$ and sig. \\
\hline Conventional & 90 & 75 & .197 \\
& & & Sig. . 212 \\
\hline Step 6.1 & Iranian corpus & Non-Iranian corpus & $\chi^{2}$ and sig. \\
\hline Conventional & 70 & - & .775 \\
\hline Optional & -- & 40 & Sig. .000 \\
\hline Step 6.2 & Iranian corpus & Non-Iranian corpus & $\chi^{2}$ and sig. \\
\hline Optional & 55 & 30 & .253 \\
& & Sig. .110 \\
\hline Step 6.3 & Iranian corpus & Non-Iranian corpus & $\chi^{2}$ and sig. \\
\hline Conventional & 75 & 90 & .197 \\
& & & Sig. . .212 \\
\hline Step 7.1 & Iranian corpus & Non-Iranian corpus & $\chi^{2}$ and sig. \\
\hline Conventional & 80 & 95 & .227 \\
& & & Sig. . 151 \\
\hline Step 7.2 & Iranian corpus & Non-Iranian corpus & $\chi^{2}$ and sig. \\
\hline Conventional & 75 & 95 & .280 \\
& & & Sig. .077 \\
\hline Step 7.3 & Iranian corpus & Non-Iranian corpus & $\chi^{2}$ and sig. \\
\hline Conventional & 85 & 90 & .076 \\
& & & Sig. .633 \\
\hline
\end{tabular}

The only statistically significant difference was found between the two corpuses in Step 6.1 (Indicating limitations), as the highest frequency in the Iranian corpus belonged to the conventional category and that of the non-Iranian corpus was optional. The null hypothesis could be, thus, rejected.

\section{Discussion OF FINDINGS}

What we found in the present research could be linked to the findings of several studies or the points raised by several scholars reviewed in the first and second chapters. As an instance, Posteguillo (1999) used Swales' eight-move version of analyzing Discussions in his genre analysis of Discussion and Conclusion sections of 30 computer science articles. He found a cyclic pattern between the moves and 'Statement of Results' as a key obligatory element. What distinguishes Posteguillo's research from the present study is first the model it adopted and then the corpus used which contained academic articles and not theses. Swales (1990) considered 'Statement of results' as a quasi-obligatory move and Posteguillo found it as an obligatory move. Similarly, here in the Iranian corpus, 'Reporting results' was found as an obligatory move. In the non-Iranian corpus, 'Commenting on results' was found as an obligatory move. This can establish a similarity of the two corpuses (i.e. academic articles and theses).

Atai and Fallah (2005) compared the genre of Discussion sections in academic articles written by English speaking researchers and Iranians. They found that 'Statement of Results' was the most frequent in both corpuses. This is in line with what we found in the present research with the Iranian corpus in which 'Reporting results' and 'Commenting on results' were found as the most frequent.

Nguyen and Pramoolsook (2015) analyzed the move structure of Results and Discussion in a sample of TESOL Master theses written by Vietnamese students. Their analysis indicated that only 'Reporting major findings' is obligatory and the first four moves which showed the rhetorical functions of summarizing, evaluating and deducing from the reported study of M.A. thesis Discussion section occurred frequently. Contrary to the present research, this study lacked a comparative approach between corpuses. It only included a national corpus which we can now compare to the national corpus of ours (Iranian corpus). The similar finding is that in the Iranian corpus too, 'reporting results' was found as an obligatory move.

In the Iranian context, Nadoushan (2012) also investigated the move structure of the Discussion sections of MA theses written in English by Iranian EFL students and compared its results with a study by Rasmeenin (2006) on the Discussion sections of 9 theses written by non-Iranian EFL students. He also indicated optional and obligatory moves and the frequency of each. According to his study, it was shown that Move 2 (Reporting results) was the most frequent. Move 5 (Summarizing the study) and move 6 (Evaluating the study) were the least frequent. In the present study, in the Iranian corpus, the most frequent Moves turned out to be 'Reporting results' and 'Summarizing results' while the least frequent was 'Summarizing the study'. These are very similar and show commonalities traced in the Iranian context. Zekrati (2015) also analyzed the genre of 32 Discussion sections of Medical Articles written by Iranian and non-Iranian nonnative authors. Based on the results of this study it was revealed that 'Reporting the results' was the most frequent 
move, and the least frequent move was 'Summarizing the study'. This is also confirmed by the present research though the corpuses are different, one being research articles and the other being M.A. theses.

\section{CONCLUSIONS AND IMPLICATIONS}

The overall findings were that the distribution of Moves and Steps in the Discussion section varies within and between the Iranian and non-Iranian corpuses. Iranian TEFL M.A. thesis writers tend more to report the results and summarize them in the Discussion sections than any other thing. They tend least to summarize the study. However, English-speaking TEFL M.A. thesis writers tend most to provide background information and comment on the results in the Discussion sections and pay the least attention to summarizing the results.

The distribution of obligatory, conventional and optional moves and steps varies within and between Iranian and nonIranian corpuses. In Iranian TEFL M.A. theses, providing background information, commenting on results and reporting results are obligatory moves while in the non-Iranian Discussions, only the first two are obligatory. Englishspeaking TEFL M.A. thesis writers tend to indicate limitations in the Discussion section significantly more than Iranian writers. This shows Iranian TEFL M.A. writers are more reserved to discuss limitations.

TEFL students at M.A. level learn, during their academic years, how to write their thesis. They get acquainted with the sections and sub-sections of thesis and are often provided with a template before preparing a draft of their thesis in advance to their defense. Yet, they are scarcely familiarized with the further constituent Moves and Steps of each main section especially the Discussion section of thesis which is expected to follow the main findings but precede the conclusive remarks which end the main content of a thesis. In other words, Discussion section occupies a sensitive part in a thesis and students are not well familiarized with what to include in it and basically in what preferred order. The present findings show Iranian TEFL students at M.A. level tend to summarize the study to the minimum in their Discussion section of thesis. They should be made aware of the significance of this Move. They are good at summarizing the results, but not that proficient in commenting on results, at least not as proficient as their English peers. They should be also encouraged to more openly express the limitations of their study.

\section{SUGGESTIONS FOR FURTHER RESEARCH}

Genre analysis of Moves and Steps has been predominant in research articles. Dissertations and theses have been less the target of genre analysis, especially in the TEFL or applied linguistics domain, and yet more specifically in the context of Iran. Moreover, different models of genre analysis prevail including that of Swales and so on. They are adopted in different works of research with little adaptation or innovation. In large corpuses, sometimes, there might be a need to adapt the model or offer a new model if the research followed a grounded theory which is conspicuously absent in the body of related literature to genre analysis. The great variety of genres especially for writing research proposals, theses or dissertations across universities (public or private sectors) in Iran provides an interesting context for comparative studies of genre analysis too. The results can provide hints for Research Methodology and Seminar courses at Iranian universities.

\section{REFERENCES}

[1] Amnuai, W. \& Wannaruk, A. (2013). Investigating Move Structure of English Applied Linguistics Research Article Discussions Published in International and Thai Journals. English Language Teaching, 6(2), 1-13.

[2] Atai, M. R. \& Falah, S. (2005). A contrastive genre analysis of result and discussion sections of applied linguistic research articles written by native and non-native English speakers with respect to evaluated entities and ascribed values. Retrieved from http://www.paaljapan.org/resources/proceedings/PAAL10/pdfs/atai.pdf (accessed 15/7/2019)

[3] Basturkmen, H. (2012). Languages for specific purposes curriculum creation and implementation in Australasia and Europe. The Modern Language Journal, 96, 59-70.

[4] Brett, P. (1994). A genre analysis of the results section of sociology articles. English for Specific Purposes, 13(1), 47-59.

[5] Chen, T.-Y. \& Kuo, C.-H. (2012). A genre-based analysis of the information structure of master's theses in applied linguistics. The Asian ESP Journal, 8(1), 24-52.

[6] Docherty, M. \& Smith, R. (1999). The case for structuring the discussion of scientific papers: Much the same as that for structuring abstracts. BMJ: British Medical Journal, 318(7193), 1224-1225.

[7] Dudley-Evans, T. (1994). Variations in the discourse patterns favoured by different disciplines and their pedagogical implications. Academic listening: Research perspectives, 146-158.

[8] Holmes, R. (1997). Genre Analysis, and the Social Sciences: An Investigation of the Structure of RA Discussion Sections in Three Disciplines. English for Specific Purposes, 16(4), 321-327

[9] Nodoushan, M. (2012, January). A structural move analysis of discussion sub-genre in applied linguistics. Dacoromania, 17(2), 199-212.

[10] Pojanapunya, P. \& Watson, R. (2009). Relevance of findings in results to discussion sections in applied linguistics research. English for Specific Purposes, 22(4), 365-385.

[11] Posteguillo, S. (1999). The schematic structure of computer science research articles. English for Specific purposes, 18(2), 139160. 
[12] Rasmeenin, C. (2006). A structural move analysis of MA thesis discussion sections in applied linguistics. Unpublished MA thesis, Mahidol University, Thailand. Retrieved from http://mulinet11.li.mahidol.ac.th/thesis/2549/cd389/4536492.pdf (accessed 05/7/2019).

[13] Sereebenjapol, P. (2003). An analysis of the errors in English which graduate science students make in the discussion section of their thesis. Unpublished MA thesis. Mahidol University, Thailand.

[14] Swales, J. (1990). Discourse analysis in professional contexts. Annual Review of Applied Linguistics, 11, 103 - 114.

[15] Swales, J. M. (2004). The manuscript version of chapter seven of Research genres: Explorations and application. Cambridge: Cambridge University Press.

[16] Swales, J.M., \& Feak, C.B. (2004). Academic Writing for Graduate Students: Essential Tasks and Skills. Ann Arbor, MI, USA: University of Michigan Press.

[17] Thetela, P. (1997). Evaluated entities and parameters of value in academic research articles. English for Specific Purposes, 16(2), 101-118.

[18] Weissberg, R. \& Buker, S. (1990). Writing up research. Englewood Cliffs, NJ: Prentice Hall. Retrieved from http://www.uefap.com/materials/history/wur.pdf (accessed 15/7/2019).

[19] Yang, R. Y. \& Allison, D. (2003). Research articles in applied linguistics: Moving from results to conclusions. English for Specific Purposes, 22(4), $365-385$.

[20] Zekrati, S. (2015). A Move Analysis of Discussion Section of Medical Articles. Taiwan International ESP Journal, 7(1), 38-50.

Yassaman Hosseini Massoum holds an M.A. of TEFL from the International University of Imam Reza in Mashhad, Iran. She has taught General courses of English in Khorasan Razavi. Her area of interest in research has been generic and analytic research. She is still affiliated with Imam Reza University.

Elham Yazdanmehr holds a Ph.D. of TEFL and is an assistant professor at Attar Institute of Higher Education. She is affiliated with Attar Institute of Higher Education. Her main areas of interest in research are teacher education and evaluation. 